\title{
A prospective longitudinal volumetric MRI study of superior temporal gyrus gray matter and amygdala-hippocampal complex in chronic schizophrenia
}

\section{Citation}

Yoshida, Takeshi, Robert W. McCarley, Motoaki Nakamura, KangUk Lee, Min-Seong Koo, Sylvain Bouix, Dean F. Salisbury, Lindsay Morra, Martha E. Shenton, and Margaret A. Niznikiewicz. 2009. A Prospective Longitudinal Volumetric MRI Study of Superior Temporal Gyrus Gray Matter and Amygdala-hippocampal Complex in Chronic Schizophrenia. Schizophrenia Research 113, no. 1: 84-94. doi:10.1016/j.schres.2009.05.004.

\section{Published Version}

doi:10.1016/j.schres.2009.05.004

\section{Permanent link}

http://nrs.harvard.edu/urn-3:HUL.InstRepos:28549057

\section{Terms of Use}

This article was downloaded from Harvard University's DASH repository, and is made available under the terms and conditions applicable to Other Posted Material, as set forth at http:// nrs.harvard.edu/urn-3:HUL.InstRepos:dash.current.terms-of-use\#LAA

\section{Share Your Story}

The Harvard community has made this article openly available.

Please share how this access benefits you. Submit a story.

\section{Accessibility}




\title{
A prospective longitudinal volumetric MRI study of superior temporal gyrus gray matter and amygdala-hippocampal complex in chronic schizophrenia
}

\author{
Takeshi Yoshida ${ }^{a, b}, c$, Robert W. McCarley ${ }^{a},{ }^{*}$, Motoaki Nakamura ${ }^{a, c}, K_{\text {KangUk Lee }}{ }^{a, c}$, Min- \\ Seong Koo ${ }^{a}, \mathrm{c}$, Sylvain Bouix ${ }^{\mathrm{a}, \mathrm{c}}$, Dean F. Salisbury ${ }^{\mathrm{a}, \mathrm{d}}$, Lindsay Morra ${ }^{\mathrm{a}}$, Martha E. \\ Shenton ${ }^{\mathrm{a}, \mathrm{C}}$, and Margaret A. Niznikiewicz ${ }^{\mathrm{a}}$ \\ ${ }^{a}$ Clinical Neuroscience Division, Laboratory of Neuroscience, Department of Psychiatry, Boston VA \\ Healthcare System, Brockton Division and Harvard Medical School, Brockton, MA, United States

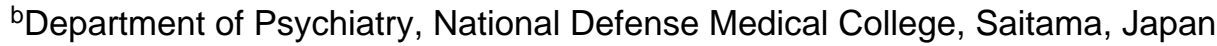 \\ 'Surgical Planning Laboratory, MRI Division, Brigham and Women's Hospital, Department of \\ Radiology, Harvard Medical School, Boston, MA, United States \\ dThe Cognitive Neuroscience Laboratory, McLean Hospital, Belmont, MA, United States
}

\begin{abstract}
A progressive post-onset decrease in gray matter volume 1.5 years after first hospitalization in schizophrenia has been shown in superior temporal gyrus (STG). However, it is still controversial whether progressive volume reduction occurs in chronic schizophrenia in the STG and amygdalahippocampal complex (AHC), structures found to be abnormal in chronic schizophrenia. These structures were measured at two time points in 16 chronic schizophrenia patients and 20 normal comparison subjects using manual tracing with high spatial resolution magnetic resonance imaging (MRI).Average interscan interval was 3.1 years for schizophrenia patients and 1.4 years for healthy comparison subjects.

Cross-sectional comparisons showed smaller relative volumes in schizophrenia compared with controls in posterior STG and AHC. An ANCOVA with interscan interval as a covariate showed there was no statistically significant progression of volume reduction in either the STG or AHC in the schizophrenia group compared with normal subjects. In the schizophrenia group, volume change in the left anterior AHC significantly correlated with PANSS negative symptoms. These data, and separately reported first episode data from our laboratory, suggest marked progression at the initial stage of schizophrenia, but less in chronic schizophrenia.
\end{abstract}

(C) 2009 Elsevier B.V. All rights reserved.

*Corresponding author. Department of Psychiatry (116A), Boston VA Healthcare System, Brockton Division, Harvard Medical School, United States, Address: 940 Belmont St., Brockton, MA 02301, United States. Tel.: +1 508583 4500x3723, +1 508 583 4500x2473; fax: +1 508586 0894. robert_mccarley@hms.harvard.edu (R.W. McCarley).

Contributors

Authors T. Yoshida, R.W. McCarley, and M.A. Niznikiewicz designed the study and wrote the protocol. Authors T. Yoshida, R.W. McCarley, and M. A. Niznikiewicz interpreted results and contributed in the writing of the manuscript. Authors T. Yoshida, R.W.

McCarley, M. A. Niznikiewicz, M. S. Koo, Lindsay Morra, and D. F. Salisbury contributed to statistical analysis. M. Nakamura and K.U. Lee contributed to the calculation of interrater reliability of region of interest. Authors T. Yoshida, S. Bouix and M. E. Shenton contributed to measurement of volume. All authors contributed to and have approved the final manuscript.

Conflict of interest

There are no conflicts of interest for any authors to declare. 


\section{Keywords}

Schizophrenia; MRI; Superior temporal gyrus; Amygdala-hippocampal complex; Prospective study; Chronic schizophrenia

\section{Introduction}

Abnormalities in superior temporal gyrus (STG) gray matter and amygdala-hippocampal complex (AHC) are among the most consistently documented findings of schizophrenia in structural magnetic resonance imaging (MRI) studies (Honea et al., 2005; Shenton et al., 2001; Wright et al., 2000). Functionally, the STG includes primary and secondary auditory cortices and a language-related area, while the amygdala and hippocampus are critical for memory functions (Squire and Zola, 1996) and affect perception (Morris et al., 1996). Volume reduction in STG has been associated with auditory hallucinations (Barta et al., 1990) and thought disorder (Shenton et al., 1992) while volume reduction in AHC has been associated with negative symptoms (Anderson et al., 2002). The significance of these structures has been also highlighted by functional MRI reports of STG and AHC abnormalities in auditory perception, language, and memory tasks (Blakemore and Frith, 2000).

Several prospective longitudinal studies suggest progression of gray matter volume reduction in schizophrenia in the period just following onset (Nakamura et al., 2007). Greater gray matter decline in left posterior STG was found in schizophrenia patients 1.5 years after first hospitalization but not in patients with affective psychosis and controls (Kasai et al., 2003a). Progressive volume reduction of temporal structures has been also reported for whole temporal lobe (DeLisi et al., 1995), as well as Heschl's gyrus/planum temporale gray matter (Kasai et al., 2003b). Conjoint progression of Heschl's gyrus volume loss and mismatch amplitude decline (Salisbury et al., 2007) in first episode schizophrenia has also been reported. Moreover, progression in temporal lobe has been reported for patients with childhood-onset schizophrenia (Gogtay et al., 2004; Rapoport et al., 1999). In addition, reduction in left and right hemispheres and right cerebellum have been reported (DeLisi et al.,1997). However, other studies failed to find progressive volume reduction in temporal lobe structures, such as in temporal lobes and hippocampus (DeLisi et al., 1997), temporal lobe and STG (DeLisi and Hoff, 2005), hippocampal and temporal lobe volumes (Wood et al., 2001), total brain volume, hippocampus and amygdala (Whitworth et al., 2005), and hippocampus and total cortex (J. Lieberman et al., 2001).

The presence of progressive volume loss in chronic schizophrenia is even more controversial with some studies finding progressive changes and others failing to find them (see Table 1 for a comprehensive review of studies and regions involved). Among them, only two studies showed progressive volume changes in STG in chronic schizophrenia (Mathalon et al., 2001; van Haren et al., 2007).

Thus, the primary purpose of this study was to evaluate prospectively the presence of a progressive volume loss in temporal structures in chronic schizophrenia. We investigated gray matter volume of STG and AHC in chronic schizophrenia patients using high spatial resolution contiguous MRI sections and highly reliable manual region of interest measurements of these brain regions. The second purpose was to elucidate the relationship between volume changes and clinical symptoms as measured with the Positive and Negative Symptoms Scale (PANSS). 


\section{Method}

\subsection{Subjects}

Sixteen male patients with chronic schizophrenia and 20 healthy male comparison subjects participated in this study. Patients were recruited from the VA Boston Healthcare SystemBrockton Division. The comparison subjects were recruited through newspaper advertisements. After a complete description of the study, written informed consent was obtained from all participants.

Demographic data for subjects in each group are presented in Table 2. Exclusion criteria for both groups were: 1) neurological illness or major head trauma, 2) previous treatment with electric convulsive therapy (ECT), 3) any history of alcohol or drug dependence, or 4) alcohol or drug abuse within the past 5 years. The age range for inclusion was 24 to 54 years. Comparison subjects were screened with the Structured Clinical Interview for DSM-III-R (SCID), nonpatient edition, by trained interviewers (M.E.S, P.N). No comparison subjects had an Axis I psychiatric disorder in themselves or a first degree relative. All patients were diagnosed with schizophrenia based on a SCID interview and a chart review by the same interviewers. All patients were receiving neuroleptic medication (typical, $N=3$; atypical, $N=11$; both, $N=2)$. The mean dose was $392.8 \mathrm{mg} /$ day $(\mathrm{SD}=330.9)$ in chlorpromazine equivalents.

\subsection{Clinical evaluations}

Handedness was assessed with the Edinburgh Inventory (Oldfield, 1971). Subjects' and parental socioeconomic status were measured by the Hollingshead two-factor index ( $1=$ highest, 5=lowest). All subjects were given PANSS at initial scan (time 1) but not at rescan (time 2) (Table 2). In the present study, we focused on correlations between regions of interest and clinical positive and negative symptoms.

\subsection{MRI image acquisition and processing}

MR images were acquired with a 1.5-T General Electric scanner (GE Medical Systems, Milwaukee) at the Brigham and Women's Hospital in Boston. Imaging methods have been described in detail elsewhere (Wible et al., 1995). The same acquisition protocol was used at time 1 and time 2. The acquisition protocol included two MRI pulse sequences. The first sequence resulted in contiguous spoiled gradient-recalled images (repetition time $=35 \mathrm{~ms}$, echo time $=5 \mathrm{~ms}$, one repetition, $45^{\circ}$ nutation angle, $24-\mathrm{cm}$ field of view, number of excitations $=1$, matrix $=256 \times 256[192$ phase-encoding steps $] \times 124$ ). Voxels were $0.9375 \times 0.9375 \times 1.5 \mathrm{~mm}$. Data were formatted in the coronal plane and analyzed as 124 coronal $1.5-\mathrm{mm}$-thick slices. The second acquisition sequence resulted in axial series of contiguous double-echo (proton density and $\mathrm{T}_{2}$-weighted) images (repetition time $=3000 \mathrm{~ms}$, echo time $=30$ and $80 \mathrm{~ms}, 24-\mathrm{cm}$ field of view, and an interleaved acquisition with $3.0-\mathrm{mm}$ slice thickness). The voxel dimensions were $0.9375 \times 0.9375 \times 3.0 \mathrm{~mm}$. This latter pulse sequence was used to measure the volume of the total intracranial contents (brain, CSF, connective tissue, and blood vessels). An anisotropic diffusion filter (Gerig et al., 1992) was applied to both spoiled gradient-recalled and $T_{2}$ images to reduce noise prior to processing. The intensity information from both the spoiled gradient-recalled and $\mathrm{T}_{2}$ images was used in a fully automated segmentation program to classify tissue into gray matter, white matter, and CSF. An iterative expectationmaximization algorithm estimated image intensity inhomogeneities, applied intensity corrections on the basis of these estimates, and then classified tissue on the basis of the same set of signal intensity parameters for all subjects (Wells Wet al., 1996). Images were realigned by using the line between the anterior and posterior commissures and the sagittal sulcus to correct head tilt and then were resampled into isotropic voxels $(0.9375 \times 0.9375 \times 0.9375$ $\mathrm{mm}^{3}$ ). Manual drawings of regions of interest were performed on the realigned and resampled coronal slices. 


\subsection{Regions of interest}

The STG and AHC were delineated manually on a work-station by a rater who was blinded to the diagnosis and the time of scan (initial scan or rescan) with the established procedure described in our previous report (Hirayasu et al., 1998) (Fig. 1). Three raters (TY, MN, KL) who were blind to group membership independently drew the regions of interest on five subjects, resulting in a high interrater reliability (left and right anterior/posterior STG, intraclass correlation coefficients (ICC) $=0.981 / 0.995$ (left anterior/posterior) and 0.985/0.990 (right anterior/posterior); left and right anterior/posterior AHC, ICC $=0.982 / 0.990$ (left anterior/ posterior) and 0.980/0.990 (right anterior/posterior)).

\subsection{Statistical analyses}

We used $t$-tests to assess group differences at initial scan (time 1) and rescan (time 2) in age, handedness, socioeconomic status, parental socioeconomic status, education, WAIS-III, interscan interval, and total intracranial contents. The interscan interval (time between time 1 and time 2) was significantly different between groups (Table 2).

\subsubsection{Group differences in relative volume at time 1 and time 2 scans and} volume change over time-Cross-sectional group differences at time 1 and time 2 in regions of interest were evaluated using relative volumes ([absolute volume of region of interest]/[intracranial contents] $\times 100(\%)$ ) we used repeated measures analysis of variance (ANOVA) with group (schizophrenia or healthy comparison) as between-subject factor, and region (STG or AHC), subdivision (anterior or posterior), and side (left or right) as withinsubjects factors. We evaluated volume change in regions of interest over time by using the percent of change as the dependent variable. Percent volume change was calculated with the following formula: ([absolute volume at time 2]-[absolute volume at time 1])/[absolute volume at time 1$] \times 100(\%)$. An analysis of covariance (ANCOVA) with interscan interval as a covariate, group (schizophrenia or healthy comparison) as between-subject factor, subdivision (anterior or posterior) and side (left or right) as within-subjects factors was performed for STG and AHC, respectively. Finally, a regression analysis was performed to examine the effect of time between two scans on the percent volume change of the anterior/posterior STG and anterior/posterior AHC for both schizophrenia patients and healthy comparisons.

\subsubsection{Correlations between percent volume change or absolute volume and} clinical measures-Spearman's correlations were used to examine correlations between percent change and clinical symptom scales. Spearman's correlations were also used to examine correlations between absolute volume of time 1 and clinical symptom scales. In these exploratory analyses, we used $p<0.05$ as the cutoff value for statistical significance for each region.

\section{Results}

\subsection{Demographic and neuropsychological group differences}

There were no significant group differences in age, handedness, and parental socioeconomic status (Table 2). Patients had lower socioeconomic status, education, WAIS-III total score relative to comparison subjects, which is consistent with a functional deterioration brought by the disorder.

\subsection{Cross-sectional differences in relative volume at time 1 and time 2}

In the ANOVA with group, region (total STG or total AHC), subdivision (anterior or posterior), and side (left or right) for relative volume at time 1 and time 2, the groups were significantly different at both time points (time 1: $F=15.51, d f=1,34, p<0.0001$, time $2: F=18.30, d f=1,34$, 
$p<0.0001)$. Interaction of group by region by subdivision was significant both at time 1 and time 2 (time 1: $F=7.15, d f=1,34, p=0.01$, time $2: F=5.78, d f=1,34, p=0.02$ ). To follow-up on this interaction, we performed ANOVA with group, subdivision, and side separately for STG and AHC at time 1 and time 2. Interaction of group by subdivision was significant only in STG at both time points (time 1: $F=4.69, d f=1,34, p=0.04$, time 2 : $F=6.28, d f=1,34, p=0.017$ ). In ANOVA with group for anterior and posterior STG, the main effect of group was significant only in the posterior subdivision at both time points (time $1: F=7.07, d f=1,34, p=0.01$, time 2 : $F=8.08, d f=1,34, p=0.008)$ but not significant in the anterior subdivision. These results indicate the reduced volume of bilateral posterior STG in schizophrenic patients at both time 1 and time 2 (Table 3, Fig. 2a). In AHC, we performed ANOVA with group, subdivision, and side both at time 1 and time 2 . The groups were significantly different at both time points (time 1: $F=22.81, d f=1,34, \mathrm{p}<0.0001$, time $1: F=22.95, d f=1,34, p<0.0001)$. There were no significant interactions of group by subdivision at time 1 and time 2 (Table 3, Fig. 2b).

Total intracranial contents at both time 1 and time 2 were significantly smaller in schizophrenia patients than in healthy comparison subjects (time 1: $t=2.47, d f=34, p=0.02$, time $2: t=2.30$, $d f=34, p=0.03$ ) (Table 2). At the same time, intracranial contents for each group separately (i.e., in the within group comparisons) did not differ between time 1 and time 2 (for schizophrenia patients: $t=0.85, d f=15, p=0.41$; for normal comparison subjects: $t=-1.08, d f=19$, $p=0.29$ ).

\subsection{Volume change}

In STG, ANCOVA conducted on percent volume change over time with interscan interval as a covariate and group, subdivision, and side as between- and within-subjects factors did not show significant group differences $(F=0.01, d f=1,34, p=0.91)$ or significant interactions (Table 3, Fig. 3a). In AHC, ANCOVA conducted on percent change over time with interscan interval as a covariate and group, subdivision, and side showed no significant group differences $(F=0.18, d f=1,34, p=0.67)$ or significant interactions (Table 3, Fig. 3b). We also performed one factor ANCOVAs on both STG and AHC (with volumes collapsed for left and right sides) with interscan interval as covariate and group as between-subject factor. Neither region showed significant main effect of group. Finally, we performed one factor ANCOVAs on both STG and AHC (with volumes for left and right sides separately) with interscan interval as covariate and group as between-subject factor. Only right posterior AHC reached a trend level ( $F=3.07$, $d f=1,34, p=0.09$ ) (Table 3, Fig. 3b).

In the regression analyses for schizophrenia and normal controls, there were no regions which showed a significant relationship between volume change and interscan interval in either the schizophrenia or normal control group. Moreover, ANOVA with group and interscan interval to compare regression slopes between the two groups did not show significant interactions of group by interscan interval in any of the regions.

\subsection{Correlations between percent change or absolute volume and clinical measures}

There were no significant correlations between percent change in the anterior, posterior, and total regions in STG and total clinical symptom scales on PANSS. The scores of total negative PANSS negatively correlated at trend level $\left(r_{\mathrm{S}}=-0.48, p=0.06\right)$ with percent change of left anterior AHC. Total positive PANSS scores negatively correlated with absolute volume of time 1 in the left total STG $\left(r_{\mathrm{S}}=-0.59, p=0.02\right)$. In addition, hallucinatory behavior in PANSS $\left(r_{\mathrm{s}}=-0.74, p=0.001\right)$ significantly negatively correlated with absolute volume of time 1 in the left total STG (Fig. 4). 


\section{Discussion}

No statistically significant progressive volume changes over a three-year scan time interval in STG and AHC in chronic schizophrenia were found in this study despite using the same region of interest definitions and methodology as in Kasai et al. (2003a) that reported significant progressive volume loss in the left STG over 1.5 year in first episode patients. Thus, given that significant volumetric reductions were not detectable in the period twice as long as that used in the first episode study, this result strongly suggests a greater rate of volume loss in first episode relative to chronic schizophrenia patients. The small volume change (all ROI reductions were less than $3.0 \%$ ) and small to medium effect sizes (0.006-0.56) across all the regions imply that, at least for the three-year interval used in this study, putative volume reductions, if present, happen at a very slow rate. It may be the case that reductions of this magnitude are very difficult to detect in small ROI such as STG and AHC although they may be easier to detect with larger brain and CSF regions (DeLisi, 2008; Hulshoff Pol and Kahn, 2008). The long duration of illness in the subjects in the present study may have been an additional reason for the small volume changes reported here.

These different rates of progression have important implications for our understanding of brain changes in schizophrenia. Thus, for the STG, volume changes seem to be large initially after onset and then become relatively static in a chronic phase. If this scenario is correct, it would suggest the importance of early interventions insofar as pharmacotherapy and psychosocial treatment can mitigate progression.

The presence of significant cross-sectional relative volume reduction in the bilateral posterior STG at both time 1 and time 2 reported in this study is in line with previous results (Anderson et al., 2002; Shenton et al., 2001; Wright et al., 2000). We also found significant volume reduction in amygdala and hippocampus in schizophrenia in concordance with several previous studies. On the other hand, some post mortem studies did not show volume reduction in schizophrenia. However, post mortem findings could be complicated by several aging factors.

Volume change over time reached trend level in the right posterior AHC, which may imply a slow progressive volume loss in chronic schizophrenia. A recent volumetric MRI study reported significant association between right hippocampal volume reduction and total PANSS change in chronic schizophrenia, suggesting the possibility of progressive reduction of right hippocampus (Panenka et al., 2007). Only a longitudinal study with multiple measurement points can address this possibility and such a study is currently in progress in our laboratory.

We note that limitations of this study include a small sample size, only male participants, only two time scan points, and different interscan intervals for the patient and control groups. While we used interscan interval as a covariate to compensate statistically for the group difference in the interscan intervals, having the same interscan interval for both controls and patients would have been more desirable. In addition, atypical antipsychotic administration has been reported to be associated with changes in gray matter volume in humans, both with a possible neuroprotective effect (Konradi and Heckers, 2001; J. A. Lieberman et al., 2005;Nakamura et al., 2007) and also with a possible increase in gray matter loss reported in humans (Cahn et al., 2002) and in animals (Dorph-Petersen et al., 2005). In our study, 13 out of 16 schizophrenia patients used atypical neuroleptic drugs. Finally, because we did not measure whole brain volume or whole brain gray matter, nor any ROI other than STG and AHC, we cannot state whether cross-sectional volume reductions are specific to these ROIs, nor can we be sure whether our findings are specific to the amygdala or hippocampal component of the AHC.

The precise neurobiological mechanism of structural abnormalities and their progression in schizophrenia is unclear. However, a growing body of evidence implicates abnormal interaction of neurons using excitatory amino acid neurotransmission and those using 
GABAergic neurotransmission (Lewis and Gonzalez-Burgos, 2006). Although still controversial, this reduction of GABAergic neurotransmission and resulting increased excitation is regarded as a possible cause of neuropil (dendrites and synapses) volume reduction. Interestingly, increased levels of glutamine in medial prefrontal cortex (Bartha et al., 1997; Olbrich et al., 2008) and anterior cingulate cortex and thalamus (Theberge et al., 2002, 2007), glutamate in dorsolateral prefrontal cortex and hippocampus (van Elst et al., 2005), and cerebrospinal fluid (Hashimoto et al., 2005)were found in first episode and early schizophrenia, while lower levels of glutamine and glutamate in anterior cingulate and thalamus (Theberge et al., 2003) and glutamate/glutamine in dorsolateral prefrontal cortex (Ohrmann et al., 2007, 2005) were found in chronic schizophrenia. These different levels of glutamatergic dysfunction in several regions at different stages in schizophrenia may explain the difference between progressive volume change in the early stage of schizophrenia and a lack of such changes in the chronic stage. Thus, in temporal lobe structures, the pathophysiological processes may differ between the early and late stages after the onset of psychosis in schizophrenia.

Consistent with this hypothesis, there were reports of stable longitudinal mismatch negativity $(\mathrm{MMN})$ deficits in test-retest measurements over 1-2 years duration in patients with chronic schizophrenia (Light and Braff, 2005). This contrasts dramatically with progression of deficits over 1.5 years in a longitudinal study of patients with initial measurements at first hospitalization and time 2 measurements 1.5 years later (Salisbury et al., 2007). Moreover, the Salisbury et al. (2007) study found the change in MMN to be correlated with volume reduction in Heschl's gyrus, consistent with evidence of a MMN generator in STG (Alho, 1995; Naatanen, 1992; Sabri et al., 2004), and with NMDA as a primary neurotransmitter contributing to MMN generation (Javitt et al., 1996; Kreitschmann-Andermahr et al., 2001; Umbricht et al., 2000). The absence of progressive volumetric changes in the STG and stable MMN deficits in chronic schizophrenia may thus reflect a common pathophysiological basis of increased GABAergicglutamatergic dysfunction in STG during the early course of schizophrenia and less in chronic schizophrenia.

In clinical correlations, the left anterior AHC volume reduction, mainly including left amygdala, correlated with total negative PANSS scores at trend level. This area has been reported to be related to negative symptoms of schizophrenia (Rajarethinam et al., 2001). It is unclear why, in our study, negative symptoms inversely correlated only with volume change over time, but not with relative or absolute volume. However, the present findings suggest that the volume change of the left amygdala over time may contribute to negative symptoms during a chronic course of schizophrenia. Smaller left total STG was associated with severity of hallucinatory behavior. Left STG has been reported to be associated with auditory hallucinations in schizophrenia in studies using several functional modalities (Copolov et al., 2003; Hoffman et al., 2003; Ropohl et al., 2004; van de Ven et al., 2005). Absolute volume of the left total STG also negatively correlated with total positive PANSS scores indicating that volume reductions of left STG may contribute to global positive symptoms in chronic schizophrenia.

In summary, progressive volume change of the STG and AHC was not found in chronic schizophrenia in our study suggesting that the absence of further volume reduction over time may characterize the chronic course in schizophrenia, in contrast with peri-onset period. In addition, percent change of left anterior AHC was correlated at trend level with negative symptoms, which suggests an important role of this region in pathophysiology of negative symptoms in chronic schizophrenia. The correlations between positive symptoms and the volume of left STG highlighted its possible involvement in hallucinations. Further studies with a follow-up over a longer period of time are needed to clarify the nature of course in schizophrenia. 


\section{Abbreviations}

STG, superior temporal gyrus; AHC, amygdala-hippocampal complex.

\section{Acknowledgments}

The authors gratefully appreciate administrative support of Ms. Marie Fairbanks and Ms. Kristine M. Pike, and research assistance of Erin E. Connor, B.A., Matthew S. Koskowski, B.A., Lida Ungar, B.A., and Mark Dreusicke, B.A.

Role of funding source

Supported by the Department of Veterans Affairs Merit Awards (RWM, MES), a VA Schizophrenia Center award (RWM, MES), by grants from the National Institute of Mental Health [K02 MH 01110 and R01 MH 50747 to MES, R01 MH 40799 and R01 MH 052807 to RWM, CIDAR P50MH080272 (RWM and MES), NIMH R03 MH 078036 (MAN)], Japan Self Defense Force (TY), and Kangwon National University (KL). These funding bodies had no influence on study design, collection, analysis and interpretation of data, writing of the report or on decision to submit the study for publication.

\section{References}

Alho K. Cerebral generators of mismatch negativity (MMN) and its magnetic counterpart (MMNm) elicited by sound changes. Ear Hear 1995;16(1):38-51. [PubMed: 7774768]

Anderson JE, Wible CG, McCarley RW, Jakab M, Kasai K, Shenton ME. An MRI study of temporal lobe abnormalities and negative symptoms in chronic schizophrenia. Schizophr. Res 2002;58(2-3): 123-134. [PubMed: 12409152]

Barta PE, Pearlson GD, Powers RE, Richards SS, Tune LE. Auditory hallucinations and smaller superior temporal gyral volume in schizophrenia. Am. J. Psychiatry 1990;147(11):1457-1462. [PubMed: 2221156]

Bartha R, Williamson PC, Drost DJ, Malla A, Carr TJ, Cortese L, Canaran G, Rylett RJ, Neufeld RW. Measurement of glutamate and glutamine in the medial prefrontal cortex of never-treated schizophrenic patients and healthy controls by proton magnetic resonance spectroscopy. Arch. Gen. Psychiatry 1997;54(10):959-965. [PubMed: 9337777]

Blakemore, SJ.; Frith, CD. Functional neuroimaging studies of schizophrenia. In: Toga, AWFR.; Mazziotta, JC., editors. Brain Mapping: the Disorders. San Diego: Academic Press; 2000. p. 523-544.

Cahn W, Hulshoff Pol HE, Lems EB, van Haren NE, Schnack HG, van der Linden JA, Schothorst PF, van Engeland H, Kahn RS. Brain volume changes in first-episode schizophrenia: a 1-year follow-up study. Arch. Gen. Psychiatry 2002;59(11):1002-1010. [PubMed: 12418933]

Copolov DL, Seal ML, Maruff P, Ulusoy R, Wong MT, Tochon-Danguy HJ, Egan GF. Cortical activation associated with the experience of auditory hallucinations and perception of human speech in schizophrenia:a PET correlation study. Psychiatry Res 2003;122(3):139-152. [PubMed: 12694889]

Davis KL, Buchsbaum MS, Shihabuddin L, Spiegel-Cohen J, Metzger M, Frecska E, Keefe RS, Powchik P. Ventricular enlargement in poor-outcome schizophrenia. Biol. Psychiatry 1998;43(11):783-793. [PubMed: 9611667]

DeLisi LE. The concept of progressive brain change in schizophrenia:implications for understanding schizophrenia. Schizophr. Bull 2008;34(2):312-321. [PubMed: 18263882]

DeLisi LE, Hoff AL. Failure to find progressive temporal lobe volume decreases 10 years subsequent to a first episode of schizophrenia. Psychiatry Res 2005;138(3):265-268. [PubMed: 15854794]

DeLisi LE, Tew W, Xie S, Hoff AL, Sakuma M, Kushner M, Lee G, Shedlack K, Smith AM, Grimson R. A prospective follow-up study of brain morphology and cognition in first-episode schizophrenic patients: preliminary findings. Biol. Psychiatry 1995;38(6):349-360. [PubMed: 8547454]

DeLisi LE, Sakuma M, Tew W, Kushner M, Hoff AL, Grimson R. Schizophrenia as a chronic active brain process: a study of progressive brain structural change subsequent to the onset of schizophrenia. Psychiatry Res 1997;74(3):129-140. [PubMed: 9255858]

DeLisi LE, Sakuma M, Maurizio AM, Relja M, Hoff AL. Cerebral ventricular change over the first 10 years after the onset of schizophrenia. Psychiatry Res 2004;130(1):57-70. [PubMed: 14972368] 
Dorph-Petersen KA, Pierri JN, Perel JM, Sun Z, Sampson AR, Lewis DA. The influence of chronic exposure to antipsychotic medications on brain size before and after tissue fixation: a comparison of haloperidol and olanzapine in macaque monkeys. Neuropsychopharmacology 2005;30(9):1649_ 1661. [PubMed: 15756305]

Gerig GKO, Kikinis R, Jolesz FA. Nonlinear anisotropic filtering of MRI data. IEEE. Trans. Med. Imag 1992;11:221-232.

Gogtay N, Sporn A, Clasen LS, Nugent TF 3rd, Greenstein D, Nicolson R, Giedd JN, Lenane M, Gochman P, Evans A, Rapoport JL. Comparison of progressive cortical gray matter loss in childhood-onset schizophrenia with that in childhood-onset atypical psychoses. Arch.Gen. Psychiatry 2004;61(1):1722. [PubMed: 14706940]

Gur RE, Cowell P, Turetsky BI, Gallacher F, Cannon T, Bilker W, Gur RC. A follow-up magnetic resonance imaging study of schizophrenia. Relationship of neuroanatomical changes to clinical and neurobehavioral measures. Arch. Gen. Psychiatry 1998;55(2):145-152. [PubMed: 9477928]

Hashimoto K, Engberg G, Shimizu E, Nordin C, Lindstrom LH, Iyo M. Elevated glutamine/glutamate ratio in cerebrospinal fluid of first episode and drug naive schizophrenic patients. BMC. Psychiatry 2005;5(1):6. [PubMed: 15683541]

Hirayasu Y, Shenton ME, Salisbury DF, Dickey CC, Fischer IA, Mazzoni P, Kisler T, Arakaki H, Kwon JS, Anderson JE, Yurgelun-Todd D, Tohen M, McCarley RW. Lower left temporal lobe MRI volumes in patients with first-episode schizophrenia compared with psychotic patients with firstepisode affective disorder and normal subjects. Am.J. Psychiatry 1998;155(10):1384-1391. [PubMed: 9766770]

Hoffman RE, Hawkins KA, Gueorguieva R, Boutros NN, Rachid F, Carroll K, Krystal JH. Transcranial magnetic stimulation of left temporoparietal cortex and medication-resistant auditory hallucinations. Arch. Gen. Psychiatry 2003;60(1):49-56. [PubMed: 12511172]

Honea R, Crow TJ, Passingham D, Mackay CE. Regional deficits in brain volume in schizophrenia: a meta-analysis of voxel-based morphometry studies. Am. J. Psychiatry 2005;162(12):2233-2245. [PubMed: 16330585]

Hulshoff Pol HE, Kahn RS. What happens after the first episode? A review of progressive brain changes in chronically ill patients with schizophrenia. Schizophr. Bull 2008;34(2):354-366. [PubMed: 18283048]

Illowsky BP, Juliano DM, Bigelow LB, Weinberger DR. Stability of CT scan findings in schizophrenia: results of an 8 year follow-up study. J.Neurol. Neurosurg. Psychiatry 1988;51(2):209-213. [PubMed: 3346684]

Javitt DC, Steinschneider M, Schroeder CE, Arezzo JC. Role of cortical N-methyl-d-aspartate receptors in auditory sensory memory and mismatch negativity generation: implications for schizophrenia. Proc.Natl. Acad. Sci. U. S. A 1996;93(21):11962-11967. [PubMed: 8876245]

Kasai K, Shenton ME, Salisbury DF, Hirayasu Y, Lee CU, Ciszewski AA, Yurgelun-Todd D, Kikinis R, Jolesz FA, McCarley RW. Progressive decrease of left superior temporal gyrus gray matter volume in patients with first-episode schizophrenia. Am. J. Psychiatry 2003a;160(1):156-164. [PubMed: 12505815]

Kasai K, Shenton ME, Salisbury DF, Hirayasu Y, Onitsuka T, Spencer MH, Yurgelun-Todd DA, Kikinis R, Jolesz FA, McCarley RW. Progressive decrease of left Heschl gyrus and planum temporale gray matter volume in first-episode schizophrenia: a longitudinal magnetic resonance imaging study. Arch. Gen. Psychiatry 2003b;60(8):766-775. [PubMed: 12912760]

Kemali D, Maj M, Galderisi S, Milici N, Salvati A. Ventricle-to-brain ratio in schizophrenia: a controlled follow-up study. Biol.Psychiatry 1989;26(7):756-759. [PubMed: 2804198]

Konradi C, Heckers S. Antipsychotic drugs and neuroplasticity:insights into the treatment and neurobiology of schizophrenia. Biol. Psychiatry 2001;50(10):729-742. [PubMed: 11720691]

Kreitschmann-Andermahr I, Rosburg T, Demme U, Gaser E, Nowak H, Sauer H. Effect of ketamine on the neuromagnetic mismatch field in healthy humans. Brain. Res. Cogn. Brain Res 2001;12(1):109_ 116. [PubMed: 11489614]

Lewis DA, Gonzalez-Burgos G. Pathophysiologically based treatment interventions in schizophrenia. Nat. Med 2006;12(9):1016-1022. [PubMed: 16960576] 
Lieberman J, Chakos M, Wu H, Alvir J, Hoffman E, Robinson D, Bilder R. Longitudinal study of brain morphology in first episode schizophrenia. Biol. Psychiatry 2001;49(6):487-499. [PubMed: 11257234]

Lieberman JA, Tollefson GD, Charles C, Zipursky R, Sharma T, Kahn RS, Keefe RS, Green AI, Gur RE, McEvoy J, Perkins D, Hamer RM, Gu H, Tohen M. Antipsychotic drug effects on brain morphology in first-episode psychosis. Arch. Gen. Psychiatry 2005;62(4):361-370. [PubMed: 15809403]

Light GA, Braff DL. Stability of mismatch negativity deficits and their relationship to functional impairments in chronic schizophrenia. Am. J. Psychiatry 2005;162(9):1741-1743. [PubMed: 16135637]

Mathalon DH, Sullivan EV, Lim KO, Pfefferbaum A. Progressive brain volume changes and the clinical course of schizophrenia in men: a longitudinal magnetic resonance imaging study. Arch. Gen. Psychiatry 2001;58(2):148-157. [PubMed: 11177116]

Morris JS, Frith CD, Perrett DI, Rowland D, Young AW, Calder AJ, Dolan RJ. A differential neural response in the human amygdala to fearful and happy facial expressions. Nature 1996;383(6603): 812-815. [PubMed: 8893004]

Naatanen, N. Attentional and Brain Function. Hillsdale, NJ: Lawrence Erlbaum Associates; 1992.

Nasrallah HA, Olson SC, McCalley-Whitters M, Chapman S, Jacoby CG. Cerebral ventricular enlargement in schizophrenia. A preliminary follow-up study. Arch. Gen. Psychiatry 1986;43(2): 157-159. [PubMed: 3947210]

Nakamura M, Salisbury DF, Hirayasu Y, Bouix S, Pohl KM, Yoshida T, Koo MS, Shenton ME, McCarley RW. Neocortical gray matter volume in first-episode schizophrenia and first-episode affective psychosis: a cross-sectional and longitudinal MRI study. Biol. Psychiatry 2007;62(7):773-783. [PubMed: 17586477]

Nair TR, Christensen JD, Kingsbury SJ, Kumar NG, Terry WM, Garver DL. Progression of cerebroventricular enlargement and the subtyping of schizophrenia. Psychiatry Res 1997;74(3):141150. [PubMed: 9255859]

Ohrmann P, Siegmund A, Suslow T, Spitzberg K, Kersting A, Arolt V, Heindel W, Pfleiderer B. Evidence for glutamatergic neuronal dysfunction in the prefrontal cortex in chronic but not in first-episode patients with schizophrenia: a proton magnetic resonance spectroscopy study. Schizophr. Res 2005;73(2-3):153-157. [PubMed: 15653258]

Ohrmann P, Siegmund A, Suslow T, Pedersen A, Spitzberg K, Kersting A, Rothermundt M, Arolt V, Heindel W, Pfleiderer B. Cognitive impairment and in vivo metabolites in first-episode neurolepticnaive and chronic medicated schizophrenic patients: a proton magnetic resonance spectroscopy study. J. Psychiatr. Res 2007;41(8):625-634. [PubMed: 16949099]

Olbrich HM, Valerius G, Rusch N, Buchert M, Thiel T, Hennig J, Ebert D, Van Elst LT. Frontolimbic glutamate alterations in first episode schizophrenia: evidence from a magnetic resonance spectroscopy study. World J. Biol. Psychiatry 2008;9(1):59-63. [PubMed: 17853298]

Oldfield RC. The assessment and analysis of handedness: the Edinburgh inventory. Neuropsychologia 1971;9(1):97-113. [PubMed: 5146491]

Panenka WJ, Khorram B, Barr AM, Smith GN, Lang DJ, Kopala LC, Vandorpe RA, Honer WG. A longitudinal study on the effects of typical versus atypical antipsychotic drugs on hippocampal volume in schizophrenia. Schizophr. Res 2007;94(1-3):288-292. [PubMed: 17570643]

Rajarethinam R, DeQuardo JR, Miedler J, Arndt S, Kirbat R, Brunberg JA, Tandon R. Hippocampus and amygdala in schizophrenia: assessment of the relationship of neuroanatomy to psychopathology. Psychiatry Res 2001;108(2):79-87. [PubMed: 11738542]

Rapoport JL, Giedd JN, Blumenthal J, Hamburger S, Jeffries N, Fernandez T, Nicolson R, Bedwell J, Lenane M, Zijdenbos A, Paus T, Evans A. Progressive cortical change during adolescence in childhood-onset schizophrenia. A longitudinal magnetic resonance imaging study. Arch. Gen. Psychiatry 1999;56(7):649-654. [PubMed: 10401513]

Ropohl A, Sperling W, Elstner S, Tomandl B, Reulbach U, Kaltenhauser M, Kornhuber J, Maihofner C. Cortical activity associated with auditory hallucinations. Neuroreport 2004;15(3):523-526. [PubMed: 15094516]

Sabri M, Kareken DA, Dzemidzic M, Lowe MJ, Melara RD. Neural correlates of auditory sensory memory and automatic change detection. Neuroimage 2004;21(1):69-74. [PubMed: 14741643] 
Saijo T, Abe T, Someya Y, Sassa T, Sudo Y, Suhara T, Shuno T, Asai K, Okubo Y. Ten year progressive ventricular enlargement in schizophrenia: an MRI morphometrical study. Psychiatry Clin. Neurosci 2001;55(1):41-47. [PubMed: 11235857]

Salisbury DF, Kuroki N, Kasai K, Shenton ME, McCarley RW. Progressive and interrelated functional and structural evidence of post-onset brain reduction in schizophrenia. Arch. Gen. Psychiatry 2007;64 (5):521-529. [PubMed: 17485604]

Shenton ME, Kikinis R, Jolesz FA, Pollak SD, LeMay M, Wible CG, Hokama H, Martin J, Metcalf D, Coleman M, et al. Abnormalities of the left temporal lobe and thought disorder in schizophrenia. A quantitative magnetic resonance imaging study. N. Engl. J. Med 1992;327(9):604-612. [PubMed: 1640954]

Shenton ME, Dickey CC, Frumin M, McCarley RW. A review of MRI findings in schizophrenia. Schizophr. Res 2001;49(1-2):1-52. [PubMed: 11343862]

Squire LR, Zola SM. Structure and function of declarative and nondeclarative memory systems. Proc. Natl. Acad. Sci. U. S. A 1996;93(24):13515-13522. [PubMed: 8942965]

Theberge J, Bartha R, Drost DJ, Menon RS, Malla A, Takhar J, Neufeld RW, Rogers J, Pavlosky W, Schaefer B, Densmore M, Al-Semaan Y, Williamson PC. Glutamate and glutamine measured with 4.0 T proton MRS in never-treated patients with schizophrenia and healthy volunteers. Am. J. Psychiatry 2002;159(11):1944-1946. [PubMed: 12411236]

Theberge J, Al-Semaan Y, Williamson PC, Menon RS, Neufeld RW, Rajakumar N, Schaefer B, Densmore M, Drost DJ. Glutamate and glutamine in the anterior cingulate and thalamus of medicated patients with chronic schizophrenia and healthy comparison subjects measured with 4.0-T proton MRS. Am. J. Psychiatry 2003;160(12):2231-2233. [PubMed: 14638596]

Theberge J, Williamson KE, Aoyama N, Drost DJ, Manchanda R, Malla AK, Northcott S, Menon RS, Neufeld RW, Rajakumar N, Pavlosky W, Densmore M, Schaefer B, Williamson PC. Longitudinal grey-matter and glutamatergic losses in first-episode schizophrenia. Br. J. Psychiatry 2007;191:325334. [PubMed: 17906243]

Umbricht D, Schmid L, Koller R, Vollenweider FX, Hell D, Javitt DC. Ketamine-induced deficits in auditory and visual context-dependent processing in healthy volunteers: implications for models of cognitive deficits in schizophrenia. Arch. Gen. Psychiatry 2000;57(12):1139-1147. [PubMed: 11115327]

van de Ven VG, Formisano E, Roder CH, Prvulovic D, Bittner RA, Dietz MG, Hubl D, Dierks T, Federspiel A, Esposito F, Di Salle F, Jansma B, Goebel R, Linden DE. The spatiotemporal pattern of auditory cortical responses during verbal hallucinations. Neuroimage 2005;27(3):644-655. [PubMed: 15978843]

van Elst LT, Valerius G, Buchert M, Thiel T, Rusch N, Bubl E, Hennig J, Ebert D, Olbrich HM. Increased prefrontal and hippocampal glutamate concentration in schizophrenia: evidence from a magnetic resonance spectroscopy study. Biol. Psychiatry 2005;58(9):724-730. [PubMed: 16018980]

van Haren NE, Hulshoff Pol HE, Schnack HG, Cahn W, Mandl RC, Collins DL, Evans AC, Kahn RS. Focal gray matter changes in schizophrenia across the course of the illness: a 5-year follow-up study. Neuropsychopharmacology 2007;32(10):2057-2066. [PubMed: 17327887]

van Haren NE, Hulshoff Pol HE, Schnack HG, Cahn W, Brans R, Carati I, Rais M, Kahn RS. Progressive brain volume loss in schizophrenia over the course of the illness: evidence of maturational abnormalities in early adulthood. Biol. Psychiatry 2008;63(1):106-113. [PubMed: 17599810]

Vita A, Sacchetti E, Valvassori G, Cazzullo CL. Brain morphology in schizophrenia: a 2- to 5-year CT scan follow-up study. Acta Psychiatr.Scand 1988;78(5):618-621. [PubMed: 3266058]

Wells WGW, Kikinis R, Jolesz FA. Adaptive segmentation of MRI data. IEEE. Trans. Med. Imag 1996;15:429-442.

Whitworth AB, Kemmler G, Honeder M, Kremser C, Felber S, Hausmann A, Walch T, Wanko C, Weiss EM, Stuppaeck CH, Fleischhacker WW. Longitudinal volumetric MRI study in first- and multipleepisode male schizophrenia patients. Psychiatry Res 2005;140(3):225-237. [PubMed: 16275040]

Wible CG, Shenton ME, Hokama H, Kikinis R, Jolesz FA, Metcalf D, McCarley RW. Prefrontal cortex and schizophrenia. A quantitative magnetic resonance imaging study. Arch. Gen. Psychiatry 1995;52 (4):279-288. [PubMed: 7702444] 
Woods BT, Yurgelun-Todd D, Benes FM, Frankenburg FR, Pope HG Jr. McSparren J. Progressive ventricular enlargement in schizophrenia:comparison to bipolar affective disorder and correlation with clinical course. Biol. Psychiatry 1990;27(3):341-152. [PubMed: 2302441]

Wood SJ, Velakoulis D, Smith DJ, Bond D, Stuart GW, McGorry PD, Brewer WJ, Bridle N, Eritaia J, Desmond P, Singh B, Copolov D, Pantelis C. A longitudinal study of hippocampal volume in first episode psychosis and chronic schizophrenia. Schizophr. Res 2001;52(1-2):37-46. [PubMed: 11595390]

Wright IC, Rabe-Hesketh S, Woodruff PW, David AS, Murray RM, Bullmore ET. Meta-analysis of regional brain volumes in schizophrenia. Am. J. Psychiatry 2000;157(1):16-25. [PubMed: 10618008] 

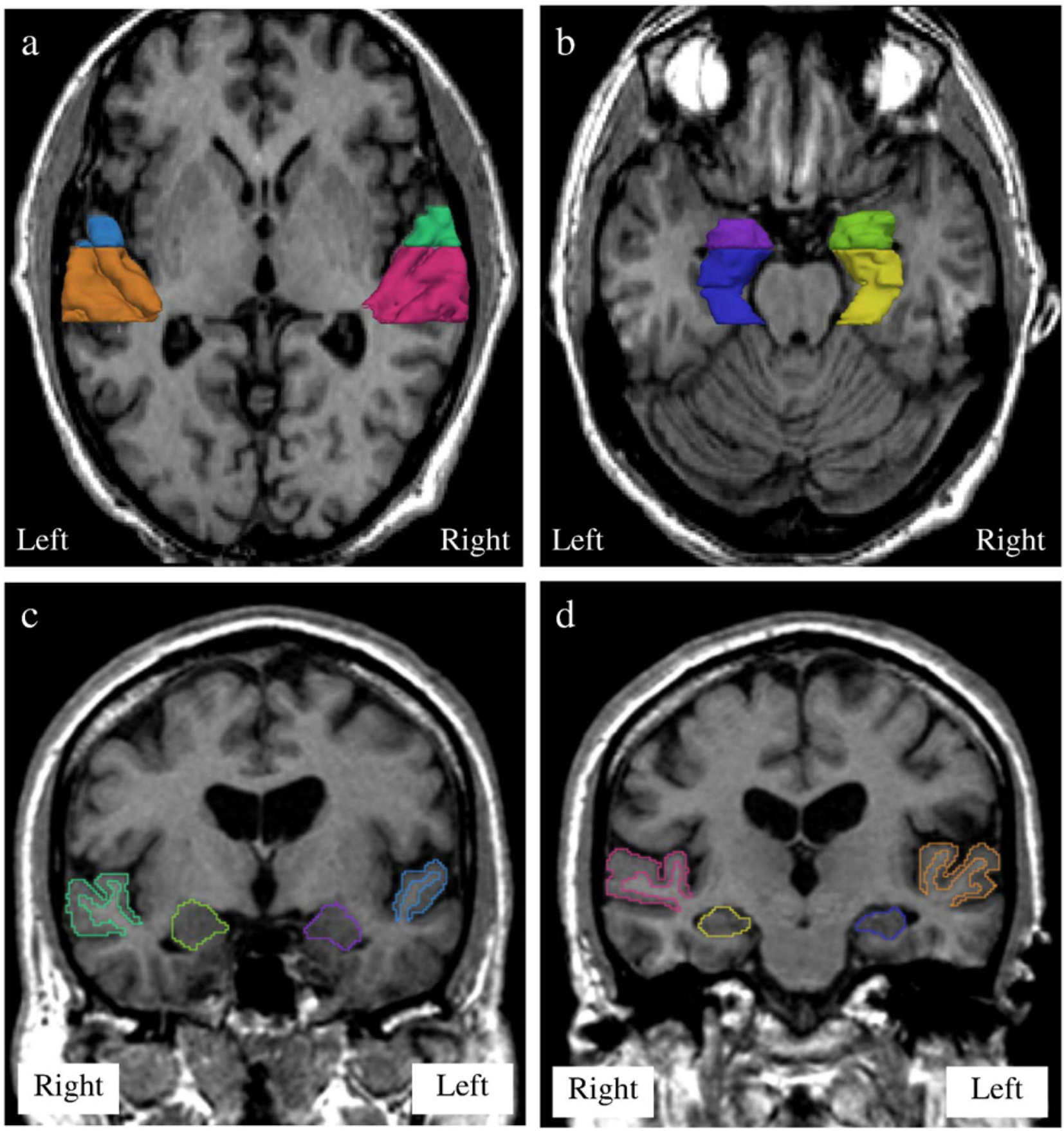

Figure 1.

Delineation of the superior temporal gyrus gray matter and amygdala-hippocampal complex. (a) Superior temporal gyrus (STG): the left and right STG gray matter are shown in axial view (right anterior STG in green, right posterior STG in red, left anterior STG in light blue, and left posterior STG in brown). (b) Amygdala-hippocampal complex (AHC): the left and right $\mathrm{AHC}$ are shown in axial view (right anterior $\mathrm{AHC}$ in light green, right posterior $\mathrm{AHC}$ in yellow, left anterior AHC in purple, and left posterior AHC in deep blue). (c) Delineation of anterior STG and AHC in coronal view. (d) Delineation of posterior STG and AHC in coronal view. 


\section{a. Superior Temporal Gyrus}

Anterior Superior Temporal Gyrus
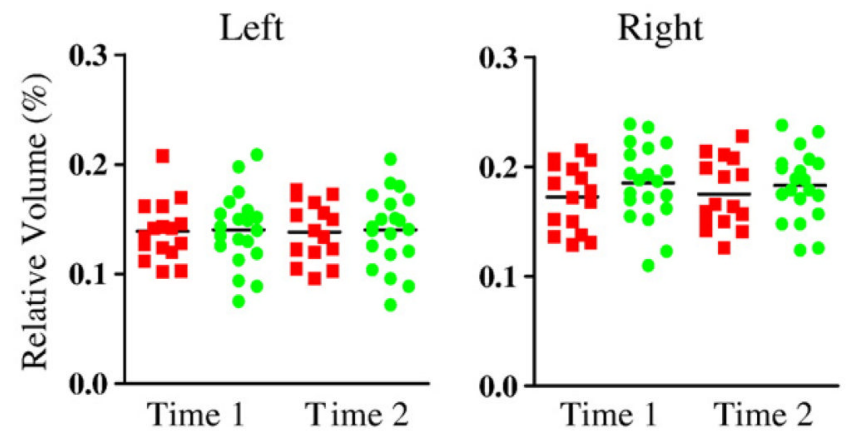

Posterior Superior Temporal Gyrus
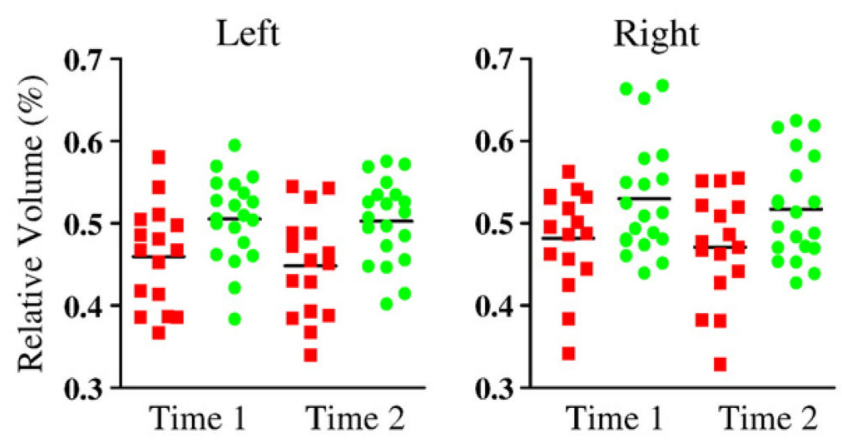

\section{b. Amygdala-Hippocampal Complex}

Anterior Amygdala-Hippocampal Complex
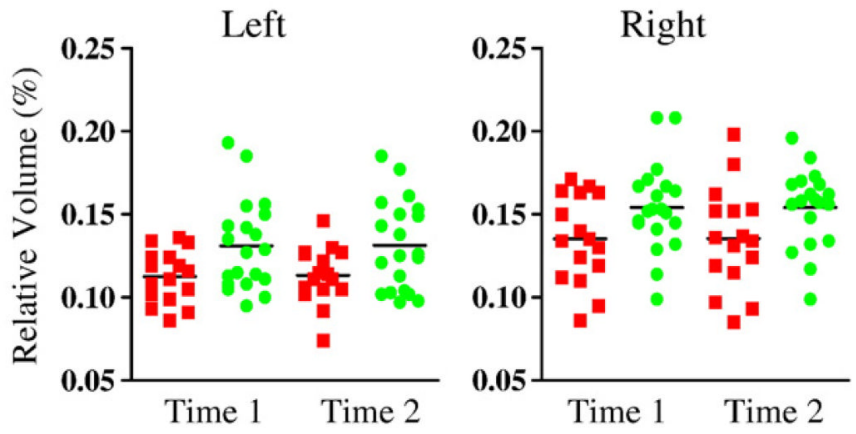

Posterior Amygdala-Hippocampal Complex
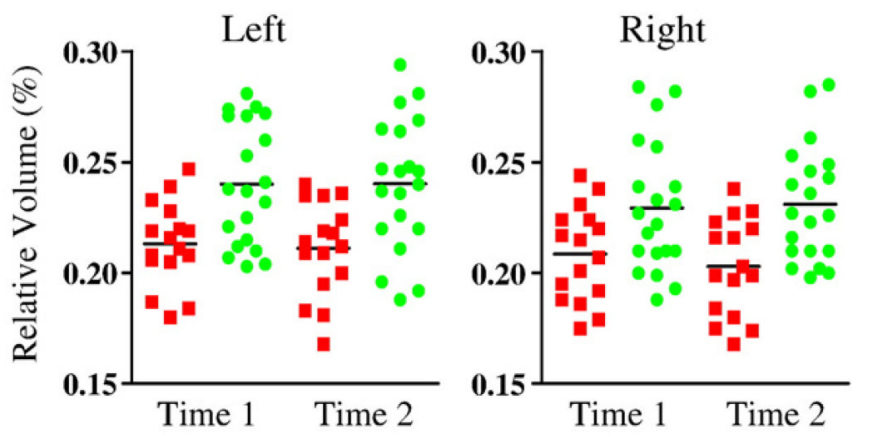

- Schizophrenia patients

- Healthy comparison subjects

Figure 2.

Relative volume of the STG and AHC by hemisphere in patients with schizophrenia and healthy comparison subjects at time 1 and time 2 (horizontal black lines indicate means). 


\section{a. Superior Temporal Gyrus}

Anterior Superior Temporal Gyrus
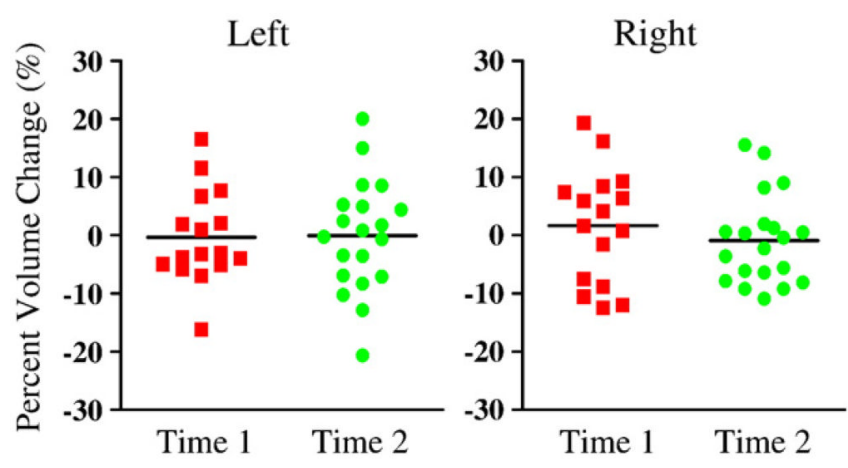

Posterior Superior Temporal Gyrus
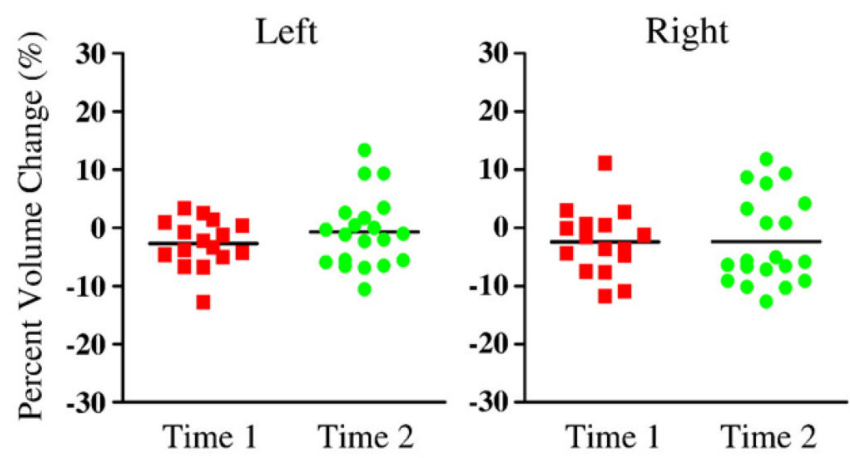

\section{b. Amygdala-Hippocampal Complex}

Anterior Amygdala-Hippocampal Complex
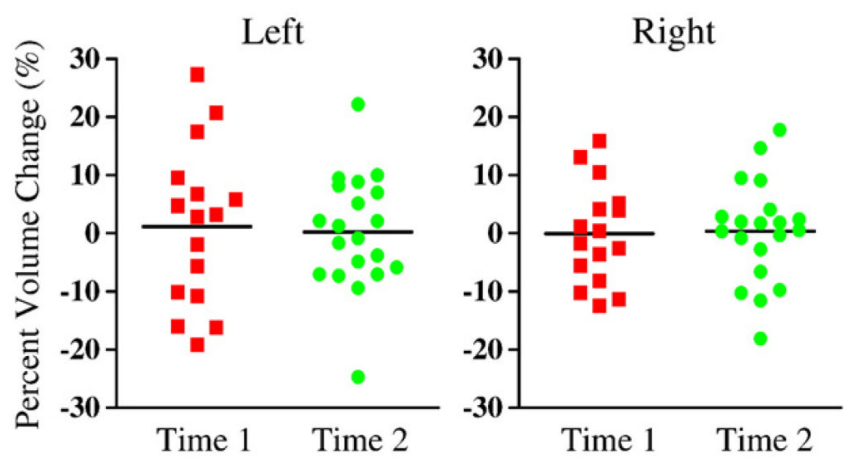

Posterior Amygdala-Hippocampal Complex
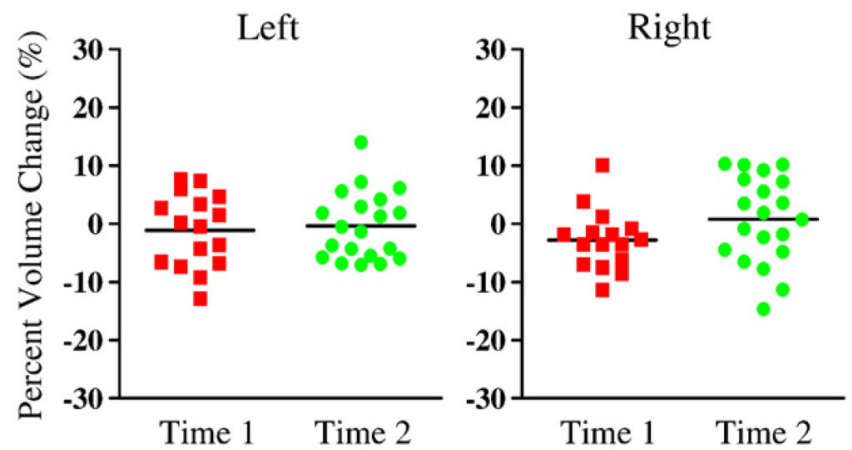

- Schizophrenia patients

- Healthy comparison subjects

Figure 3.

Percent change of the STG and AHC by hemisphere in patients with schizophrenia and healthy comparison subjects (horizontal black lines indicate means). 
Sum of negative PANSS score

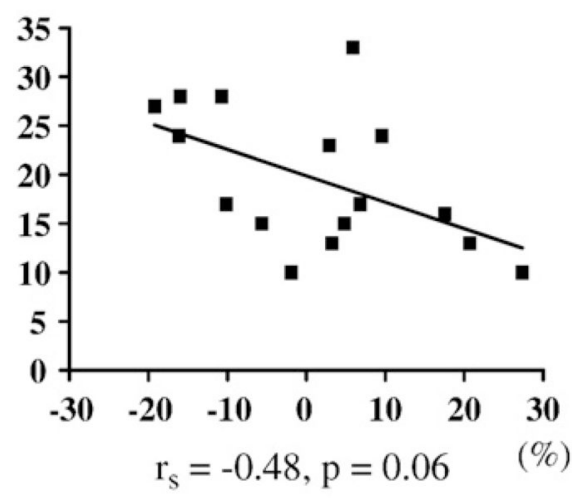

Percent change of left anterior amygdala-hippocampual complex
Sum of positive PANSS score

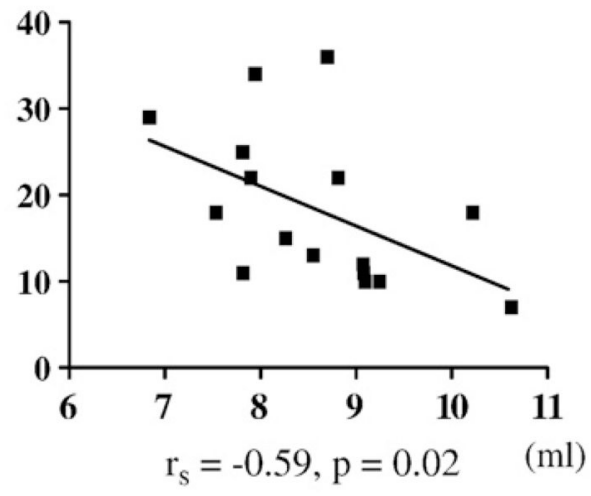

Absolute volume of left total superior temporal gyrus at time 1
Hallucinatory behavior in PANSS

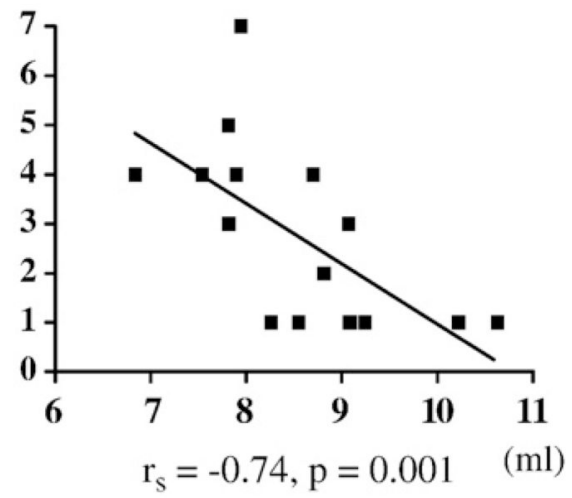

Absolute volume of left total superior temporal gyrus at time 1

Figure 4.

Correlation between percent change (left panel) or absolute volume at time 1 (middle and right panels) and clinical measure. 


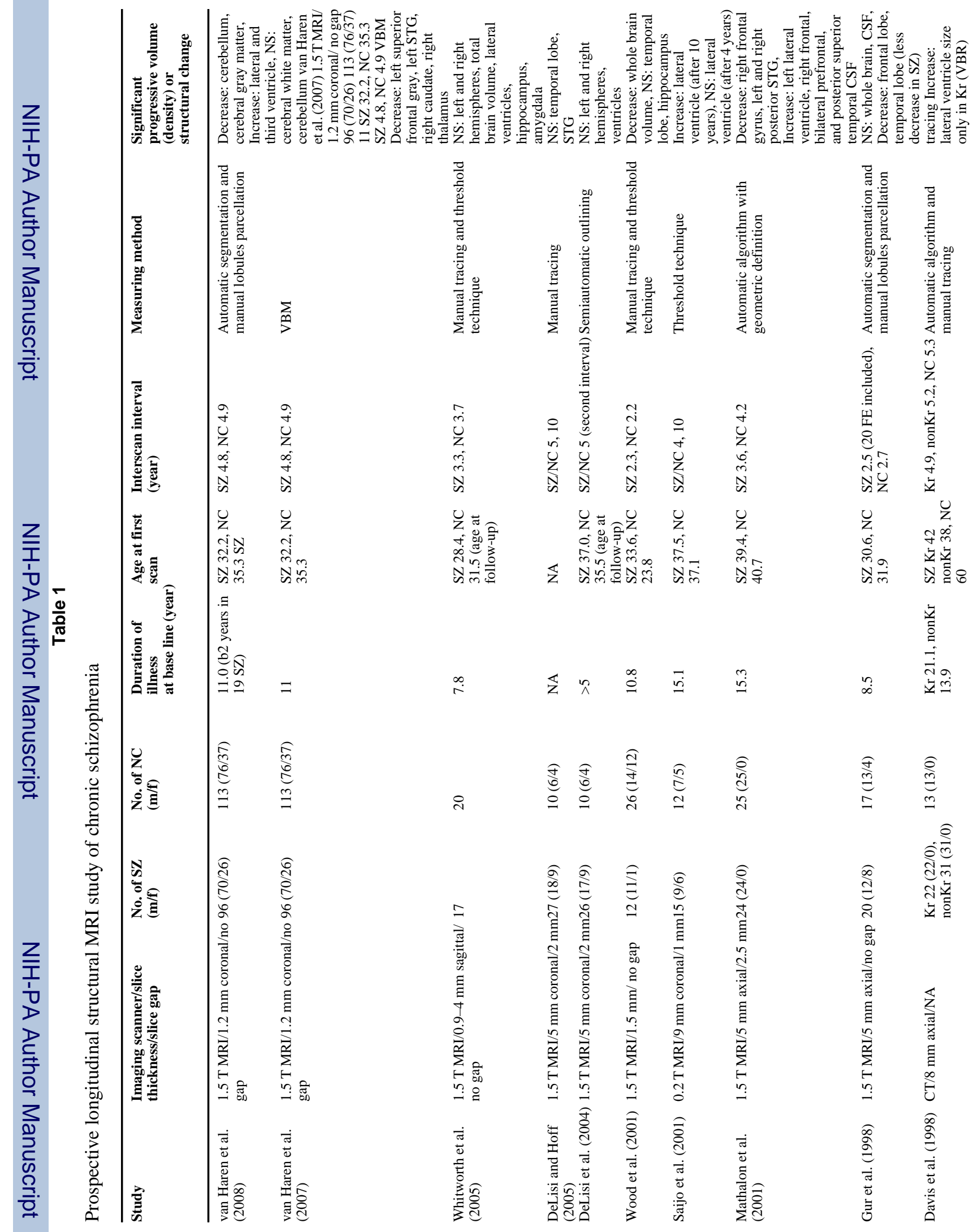




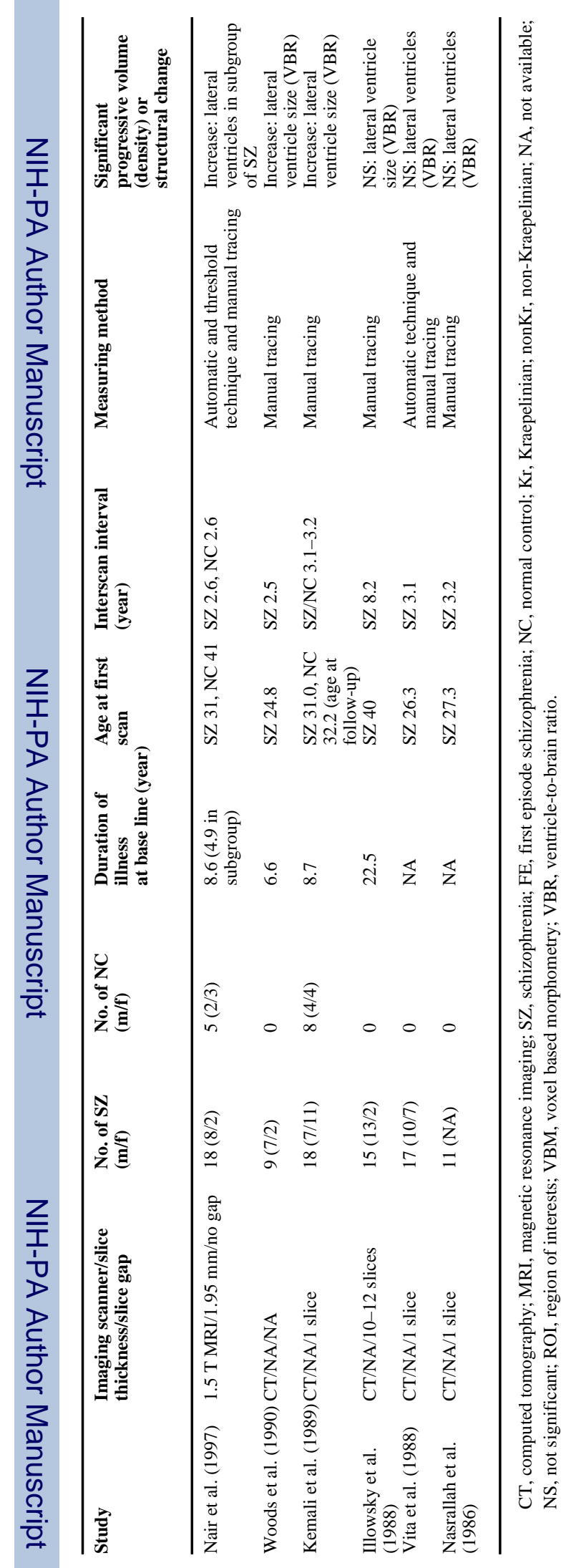

Schizophr Res. Author manuscript; available in PMC 2010 August 1. 


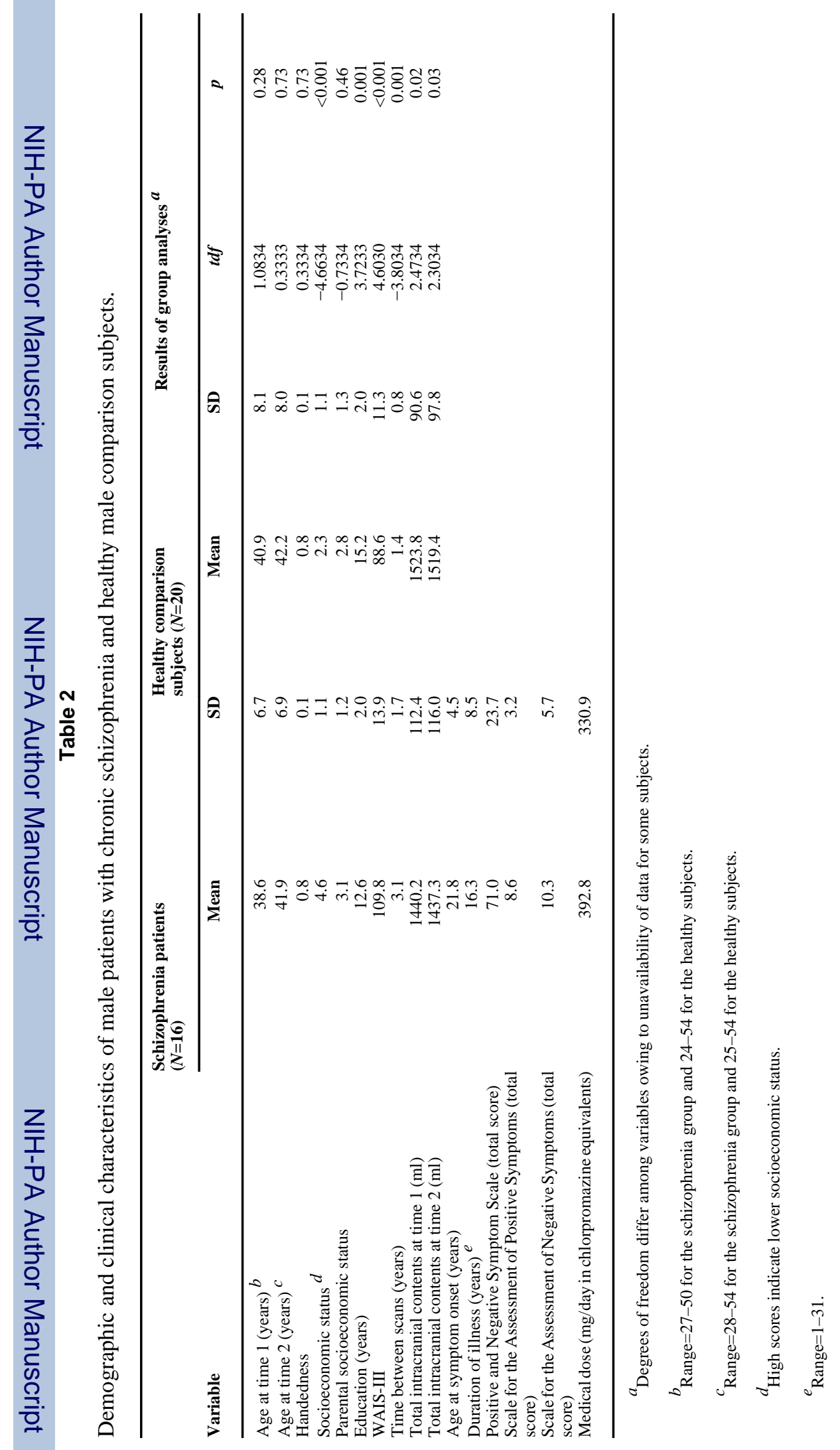


